\title{
PERANCANGAN DAN IMPLEMENTASI APLIKASI IKHTISAR KAS MASJID ISTIQOMAH BERBASIS DESKTOP
}

\author{
Amarudin 1), Agung Sofiandri' ${ }^{2)}$ \\ ${ }^{1)}$ Teknik Elektro, Universitas Teknokrat Indonesia \\ ${ }^{2)}$ Sistem Informasi, Universitas Teknokrat Indonesia \\ Jl. H.Zainal Abidin Pagaralam, No.9-11, Labuhanratu, Bandarlampung \\ Email: amarudin@teknokrat.ac.id ${ }^{1)}$,sofiandriagung79@gmail.com ${ }^{2)}$
}

\begin{abstract}
Abstrak
Ikhtisar kas masjid adalah proses penyajian informasi yang merangkum atas transaksi kas yang dikelola masjid. Masjid Istiqomah adalah salah satu masjid yang mempunyai rangkuman atas transaksi kas yaitu kas masuk dan kas keluar. Pada masjid Istiqomah sering terjadi hilangnya data yang ada dalam rangkuman atau buku catatan. Berdasarkan masalah tersebut maka perlu adanya penelitian yang dapat mempermudah dalam pendokumentasian dan pelaporan ikstisar kas masjid. Dalam penelitian tersebut dibuatlah rancangan aplikasi ikhtisar kas menggunakan metode prototype. Adapun dalam metode prototype tersebut dilakukan pengumpulan data berupa observasi, wawancara, dokumentasi dan tinjauan pustaka. Adapun dalam mendesain sistem yang dibangun menggunakan UML meliputi Use Case, Class Diagram, dan Activity Diagram. Berdasarkan hasil implementasi aplikasi ikhtisar kas tersebut didapatkan hasil bahwa aplikasi tersebut dapat berjalan dengan baik dan dapat mendokumentasikan setiap transaksi ikhtisar kas serta dapat menampilkan laporan dengan baik.
\end{abstract}

Kata Kunci : Perancangan, Implementasi, Aplikasi, Masjid Istiqomah, Ikhtisar Kas.

\section{Pendahuluan}

Informasi merupakan hal yang sangat penting bagi perusahaan baik dibidang jasa maupun perdagangan. Informasi merupakan alat yang digunakan untuk menginformasikan informasi dalam perusahaan bagi yang berkepentingan. Ada beberapa sistem informasi yang diimplementasikan dalam sebuah aplikasi berbasis desktop maupun berbasis web. Contoh implementasi aplikasi sistem informasi berbasis desktop adalah Rancang Bangun Aplikasi Kepegawaian Pegawai Negeri Sipil Dan Pegawai Honorer pada Badan Kepegawaian dan Diklat Kabupaten yang telah dibahas dalam penelitian sebelumnya oleh (Munandar and Amarudin, 2017). Sedangkan contoh penelitian lain yang berbasis web adalah Sistem Informasi Pemasangan Listrik Baru Berbasis Web Pada PT Chaputra Buana Madani Bandar Jaya Lampung Tengah (Amarudin and Silviana, 2018). Bahkan saat ini juga sudah berkembang aplikasi-aplikasi berbasis Android, contohnya aplikasi Mobile Simulasi Perhitungan Kredit Pembelian Sepeda Motor pada PT Tunas Motor Pratama yang telah dikembangkan oleh (Ahdan, Latih and Ramadona, 2018).
Beberapa sistem informasi pada aplikasi tersebut dibangun menggunakan konsep akuntansi. Sistem informasi akuntansi terdiri dari prosedur-prosedur, orangorang dan teknologi informasi, sehingga sistem informasi akuntansi mempunyai tujuan untuk mengumpulkan data dan melaporkan hasil-hasil yang berkaitan dengan keuangan sehingga informasi atau laporan tersebut dapat diketahui oleh pihak yang berkepentingan.

Informasi berupa kas pada beberapa masjid khususnya pada masjid Istiqomah biasanya sering dilakukan menggunakan pengeras suara yang ditujukan untuk memberikan informasi kepada lingkungan masyarakat bahwa masjid tersebut memiliki jumlah kas yang dilaporkan pada setiap hari jum'at, setiap bulan dan ketika terdapat musyawarah. Informasi dana kas baik yang didapat maupun yang disalurkan akan menjadi sebuah pertanyaan dari mana dan kemanakah dana tersebut didapat dan disalurkan.

Berdasarkan pengamatan dan studi kasus yang dilakukan pada masjid Istiqomah, bahwasanya untuk mengolah dana kas seperti zakat, infaq, dan shodaqoh masih dilakukan atau dicatat pada pembukuan yang menyembabkan hasil informasi sering tidak akurat. Baik dana yang diperoleh maupun dana yang disalurkan. Berdasarkan masalah ini, maka perlu adanya penelitian untuk merancang dan mengimplementasikan aplikasi ikhtisar kas berbasis desktop maupun berbasis web agar dalam pendataan dan pendokumentasian serta pelaporan ikhtisar kas masjid Istiqomah dapat berjalan dengan baik dan mudah.

Tujuan yang ingin dicapai dalam penelitian ini adalah terimplementasinya aplikasi ikhtisar kas masjid Istiqomah berbasis desktop untuk mengetahui informasi jumlah kas masuk dan kas keluar serta pelaporan ikhtisar kas dengan mudah.

\section{Pembahasan}

Ikhtisar kas masjid adalah proses penyajian informasi yang merangkum (summarizing) atas transaksi kas yang dikelola masjid. Dalam pengertian sehari-hari, masjid merupakan bangunan tempat sembahyang kaum Muslim. Namun masjid juga mengandung makna tunduk dan patuh. Hakikat masjid adalah tempat melakukan segala aktivitas yang mengandungi kepatuhan kepada Allah semata. 


\section{Metode Penelitian}

Metode penelitian yang digunakan dalam analisis dan implementasi ikhtisar kas masjifd Istiqomah dapat dilihat pada Gambar 1.

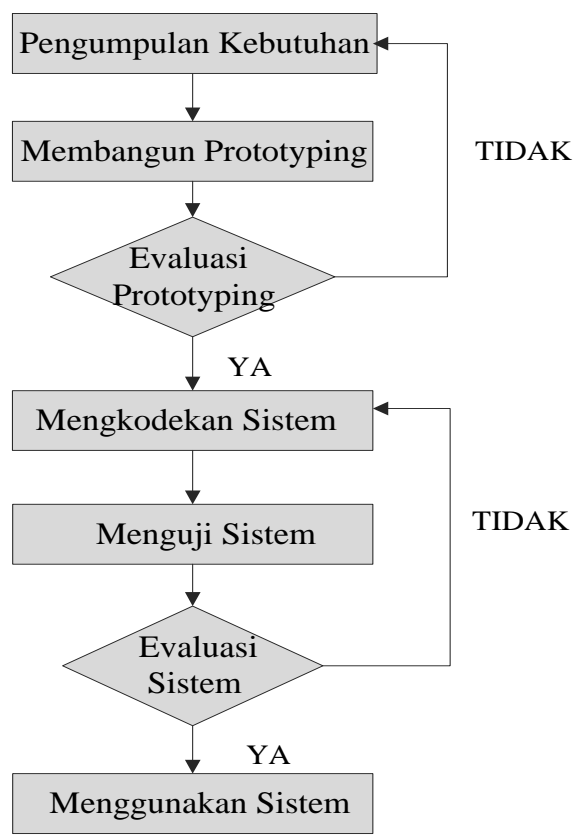

Gambar 1. Metode Prototyping (Raymond, 2007)

\subsection{Metode Pengumpulan Data}

Pengumpulan data yang dilakukan pada penelitian ini adalah sebagai berikut :

1. Wawancara (Interview)

Pengumpulan data dengan metode wawancara yaitu metode pengumpulan data dengan cara tanya jawab secara langsung dengan pihak yang mengetahui mekanismenya dan hal yang berhubungan dengan masalah yang dibahas.

2. Pengamatan (Observation)

Mengadakan pengamatan dan mempelajari sistem yang digunakan di lingkungan sistem yang sedang diteliti. Hal ini dimaksudkan agar mendapatkan gambaran yang jelas sistem yang sedang diteliti.

3. Tinjauan Pustaka

Merupakan metode pengumpulan data dengan cara membaca, mencatat, mengutip, dan mengumpulkan data-data secara teoritis dari buku-buku yang ada sebagai landasan penyusunan laporan.

\subsection{Metode Analisis}

Untuk mengidentifikasi masalah, maka harus dilakukan analisis terhadap kinerja, ekonomi, pengendalian, efisiensi, dan pelayanan atau juga sering disebut dengan analisis PIECES. Dalam penelitian ini menggunakan analisis Pieces. Menurut (Andri, 2007), analisis PIECES merupakan salah satu cara untuk mengidentifikasi masalah yang dilakukan terhadap kinerja, informasi, ekonomi, keamanan aplikasi, efesiensi dan pelayanan pelanggan. Adapun bagian-bagian analisis PIECES yaitu:

1. Analisis Kinerja (Performance)

Analisis kinerja adalah kemampuan dalam menyelesaikan tugas bisnis dengan cepat sehingga sasaran dapat segera tercapai.

2. Analisis Informasi (Information) Informasi merupakan hal yang penting bagi pengguna akhir untuk pengambilan keputusan. Evaluasi terhadap kemampuan informasi agar menghasilkan informasi yang bermanfaat.

3. Analisis Ekonomi (Economic)

Analisis ekonomi merupakan kemampuan atas penghematan biaya dan meningkatkan keuntungan perusahaan.

4. Analisis Keamanan (Security)

Analisis keamanan merupakan penilaian yang digunakan untuk mengamankan data dari kerusakan.

5. Analisis Efesiensi (Eficiency)

Analisis efesiensi merupakan pemakaian secara maksimal atas sumber daya yang tersedia meliputi manusia, informasi, waktu, dan keterlambatan pengolahan data.

6. Pelayanan (Service)

Merupakan pemecahan masalah yang terjadi agar mendapatkan pelayanan yang berkualitas.

Pada tahapan ini dilakukan analisis kebutuhan sistem yang meliputi analisis kebutuhan fungsional dan non fungsional.

\section{a) Analisis Kebutuhan Non Fungsional}

Analisis kebutuhan non fungsional dilakukan untuk mengetahui spesifikasi kebutuhan sistem. Spesifikasi kebutuhan melibatkan analisis perangkat keras (hardware), analisis perangkat lunak (software), dan analisis pengguna (user).

\section{b) Analisis Perangkat Keras (Hardware)}

Adapun spesifikasi minimal perangkat keras (hardware) yang digunakan dalam Rancang Bangun Kebutuhan Jumlah Material dengan Standar SNI ini yaitu terdiri dari:

1) Processor Dual Core $2.6 \mathrm{Ghz}$.

2) Random Access Memory (RAM) 2 GB

3) Monitor 14 inch dengan resolusi 1280 x 800 pixel.

4) Harrdisk 320 GB.

5) Keyboard, dan lain-lain.

\subsection{Metode Prototype}

Dalam penelitian ini penulis menggunakan metode Prototype, karena metode Prototype cocok digunakan untuk menjabarkan kebutuhan pengguna secara lebih detail karena pengguna sering kali kesulitan menentukan kebutuhan secara detail tampa melihat gambaran yang jelas.

\subsection{Perancangan}

Adapun pemodelan yang digunakan dalam merancang aplikasi ikhtisar kas masjid Istiqomah mengunakan UML. Menurut (Chonoles and Schardt, 2003) UML (Unified 
Modeling Language) adalah bahasa pemodelan standar yang memiliki sintaks dan semantik. Ketika kita membuat model menggunakan konsep $U M L$ ada aturan-aturan yang harus diikuti. $U M L$ hanya berfungsi untuk melakuakan pemodelan. Jadi penggunaan $U M L$ tidak hanya terbatas pada teknologi tertentu, meskipun pada kenyataannya $U M L$ paling banyak digunakan pada metodologi berorientasi objek.

\section{Use Case Diagram}

Use case diagram menggambarkan fungsionalitas yang diharapkan dari sebuah sistem yang menjelaskan keseluruhan kerja sistem secara garis besar dengan mempresentasikan interaksi antara aktor yang dibuat serta memberikan gambaran fungsi-fungsi pada sistem tersebut. Adapun use case diagram aplikasi ikhtisar kas masjid istiqomah bisa dilihat pada Gambar 1 .

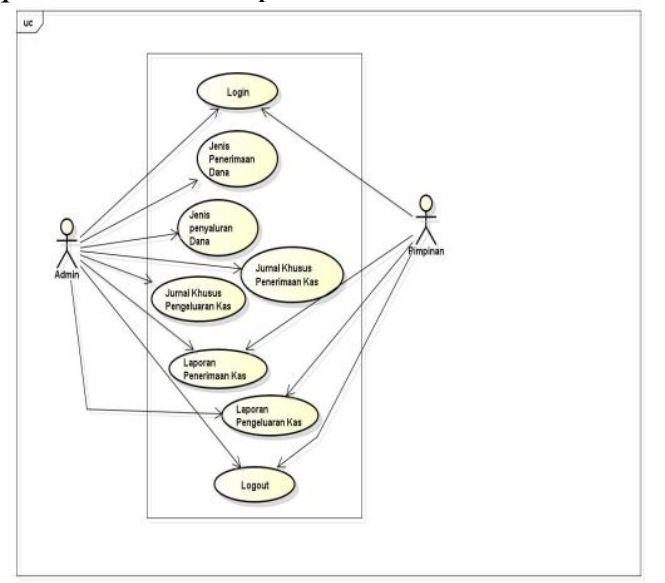

Gambar 2. Use Case Diagram

\section{Activity Diagram}

Activity diagram menggambarkan workflow (aliran kerja) dari sebuah system atau proses bisnis yang ada pada perangkat lunak. Activity Admin dan Pengguna dapat dilihat pada Gambar 3.

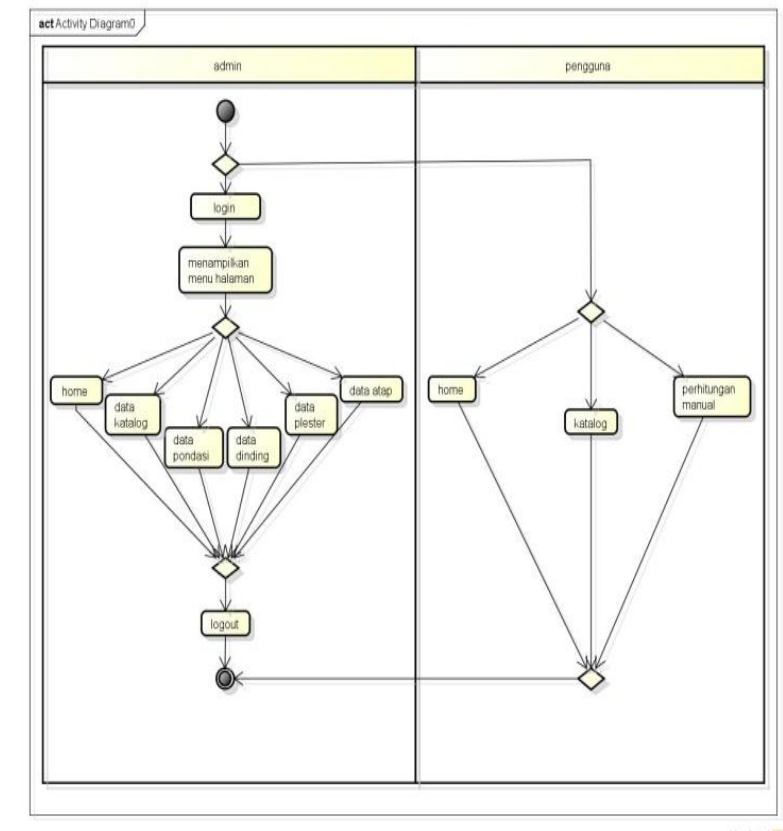

Gambar 3. Activity Diagram

\section{Class Diagram}

Diagram kelas atau class diagram menggambarkan struktur sistem dari segi pendefinisian kelas-kelas yang akan dibuat untuk membangun sistem, adapun gambar class diagram sistem ikhtisar kas masjid istiqomah bisa dilihat pada Gambar 4.

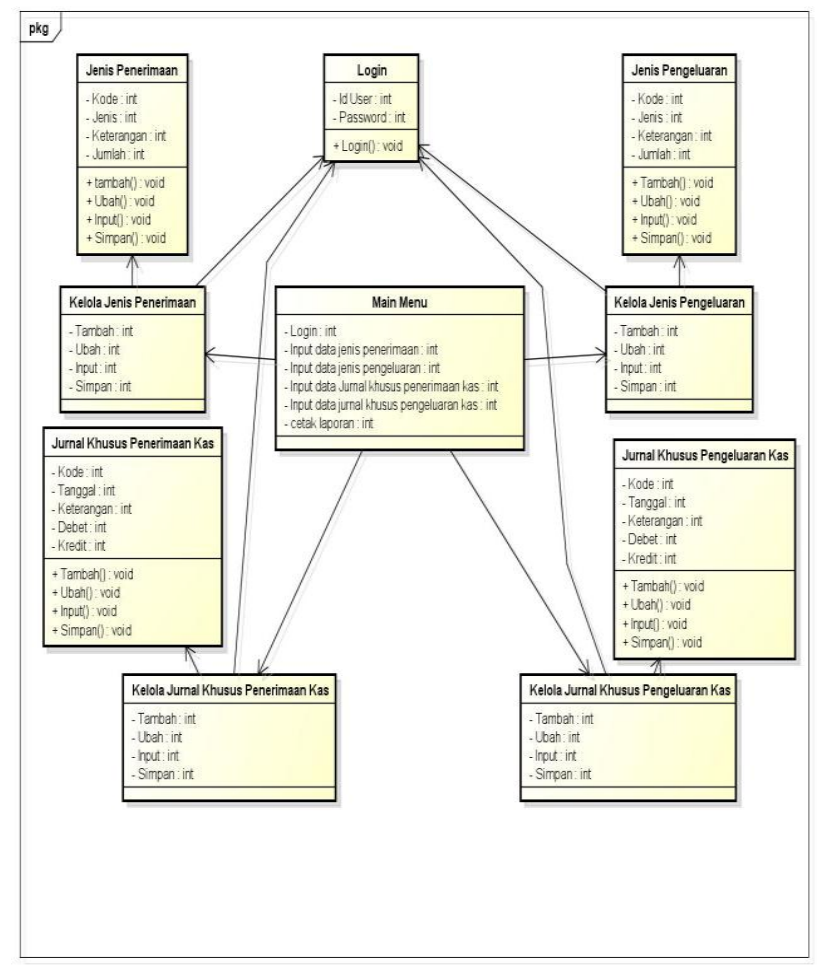

Gambar 4. Class Diagram

\subsection{Pengujian Sistem}

Sedangkan pengujian sistem pada implementasi aplikasi ini menggunakan metode Black Box. Menurut (Yakup, 2012), pengujian sistem adalah proses untuk mengecek apakah suatu perangkat lunak yang dihasilkan sudah dapat dijalankan sesuai standar atau belum. Pengujian dapat dilakukan dengan suatu cara atau metode untuk menguji perangkat lunak dan data yang kemungkinan terjadi kesalahan. Black box testing merupakan pengujian terhadap unit program yang terdapat dalam kebutuhan (requirements) yang disebutkan dalam spesifikasi.

Pada black box testing, cara pengujian hanya dilakukan dengan menjalankan atau mengeksekusi unit atau modul, kemudian diamati apakah hasil dari unit itu sesuai dengan proses bisnis yang diinginkan. Jika ada yang unit yang tidak sesuai output-nya maka akan dilakukan perbaikan kembali.

\section{Hasil dan Pembahasan}

\subsection{Hasil dan Implementasi}

Platform yang digunakan dalam penelitian ini ialah menggunakan pemrograman Borlan Delphi 7.0 dan MySQL sebagai databasenya. Pihak Masjid Istiqomah terutama pimpinan mengevaluasi sistem yang telah peneliti ujikan. Dari hasil pengujian tersebut dipastikan bahwa elemen atau komponen dari sistem telah berfungsi 
sesuai dengan yang diharapkan oleh pihak Masjid Istiqomah sehingga sistem baru siap digunakan. Berikut ini adalah hasil dari sistem yang telah diuji dan dievaluasi:

\section{Login}

Login password merupakan tampilan pertama pada saat program dijalankan.Tampilan form ini, berfungsi untuk keamanan data dimana pengguna diminta untuk meng-inputkan password yang telah ditentukan sebelumnya. Adapun tampilan form login bisa dilihat pada Gambar 5 .

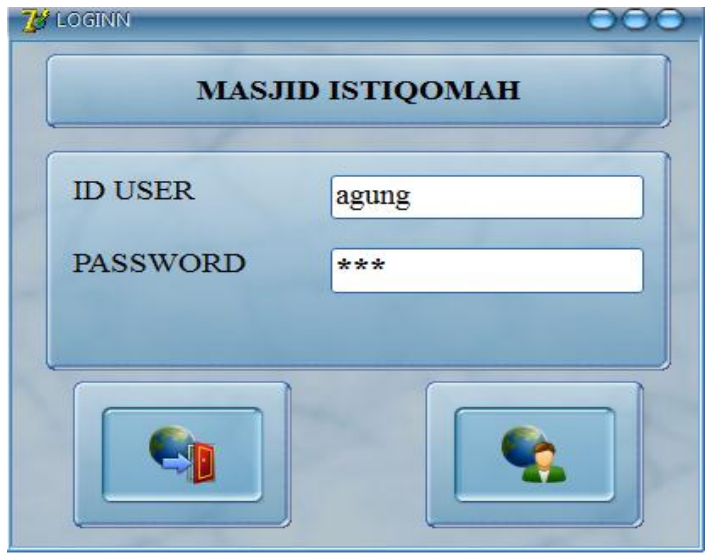

Gambar 5. Login

Form login ini merupakan tampilan awal pada sistem dijalankan. Pada form login ini terdapat pilihan nama dan password. Setelah meng-input-kan nama dan password maka dapat masuk ke menu utama sesuai dengan hak aksesnya dengan menekan tombol masuk.

\section{Menu Utama}

form menu utama merupakan bagian dimana admin dapat membuka menu file terdapat form ubah password dan keluar. Menu data inputan terdapat form input data jenis penerimaan, form input data penyaluran, form input data jurnal khusus penerimaan kas, form input data jurnal khusus pengeluaran kas, form input data laporan kas. Adapun tampilan halaman menu utama dapat dilihat pada Gambar 6 .

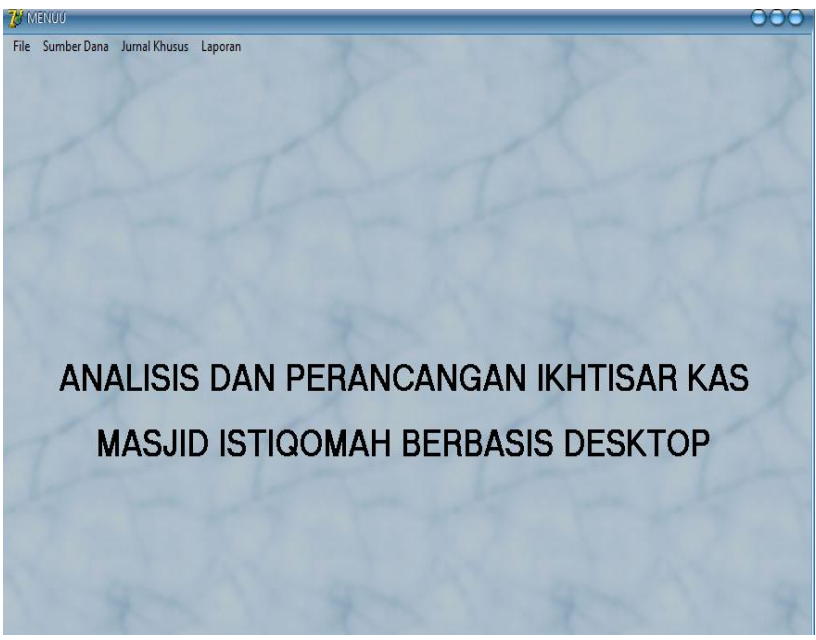

Gambar 6. Menu Utama

\section{Admin}

Form admin adalah bagian yang digunakan untuk menambah data admin atau pengguna. Tampilan Form admin dapat dilihat pada Gambar 7.

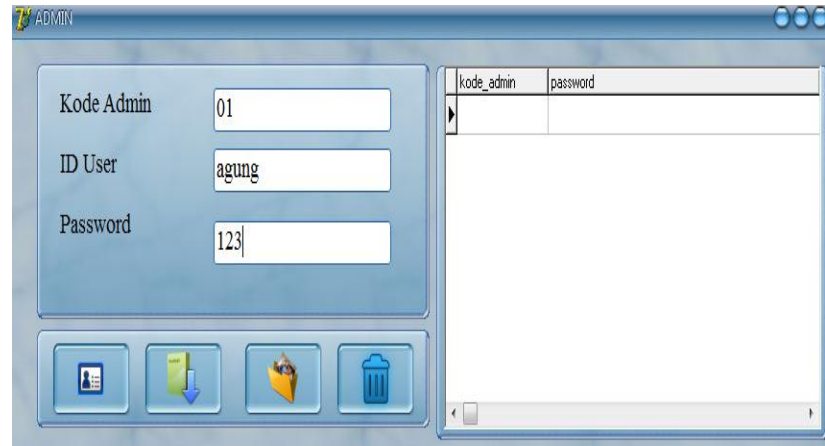

Gambar 7. Admin

\section{Input Jurnal Khusus Penerimaan Kas}

Form Input Jurnal Khusus Penerimaan Kas digunakan untuk menginput data seperti Kode Jurnal Khusus Penerimaan Kas, Tanggal, Keterangan, Debet, Kredit. Adapun form input jurnal khusus penerimaan kas dapat dilihat pada Gambar 8 .

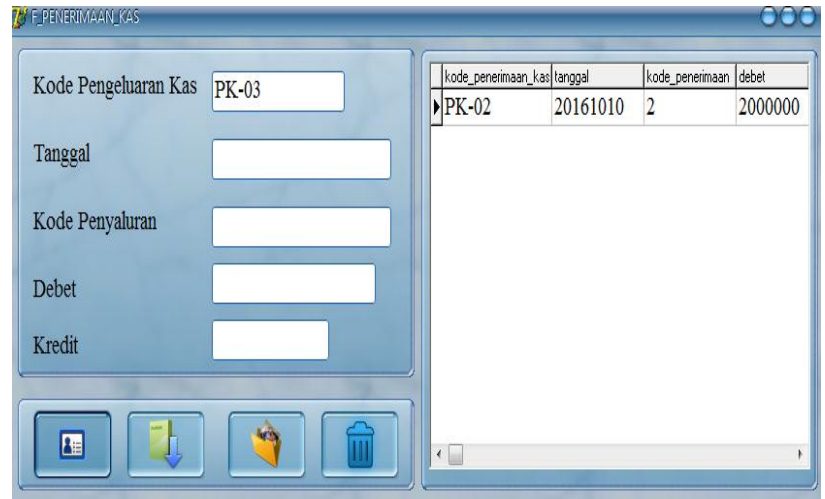

Gambar 8. Jurnal Khusus Penerimaan Kas

\section{Input Jurnal Khusus Pengeluaran Kas}

Form Input Jurnal Khusus Pengeluaran Kas digunakan untuk menginput data seperti Kode Jurnal Khusus Pengeluaran Kas, Tanggal, Keterangan, Debet, Kredit. Form input jurnal khusus pengeluaran kas dapat dilihat pada Gambar 9.

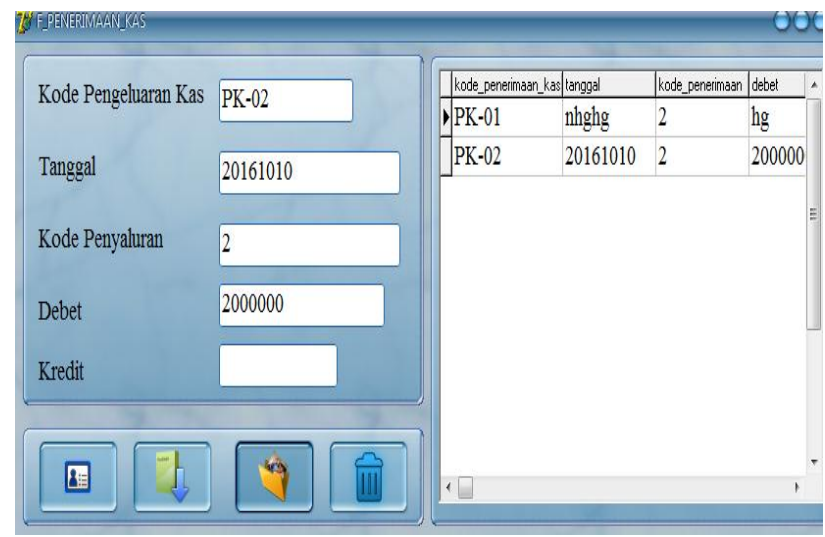

Gambar 9. Input Jurnal Khusus Pengeluaran Kas 


\section{Jenis Penerimaan Dana}

Form Jenis Penerimaan dana dapat digunakan untuk Kode Penerimaan Dana, Jenis Penerimaan Dana, Keterangan, Jumlah. Form Jenis Penerimaan Dana pada dapat dilihat pada Gambar 10.

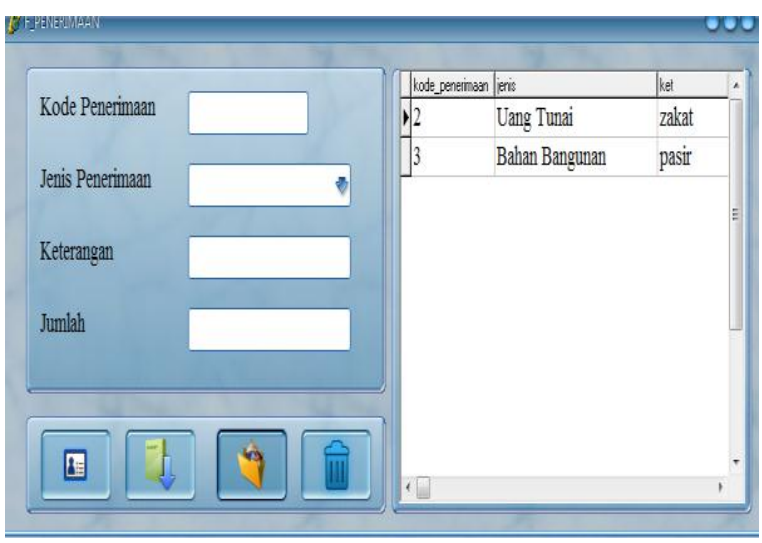

Gambar 10. Jenis Penerimaan Dana

\section{Jenis Penyaluran Dana}

Form Jenis Penyaluran dana dapat digunakan untuk Kode Penyaluran Dana, Jenis Penyaluran Dana, Keterangan, Jumlah. Form Jenis Penyaluran Dana dapat dilihat pada Gambar 11.

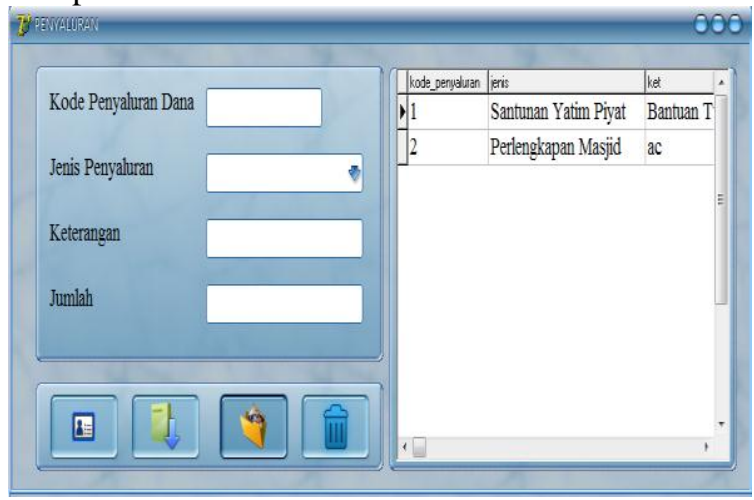

Gambar 11. Jenis Penyaluran Dana

\section{Laporan Kas Masuk}

Form Laporan Kas Masuk digunakan untuk bukti yang diberikan kepada pimpinan, Form Laporan Kas Masuk dapat dilihat pada Gambar 12.

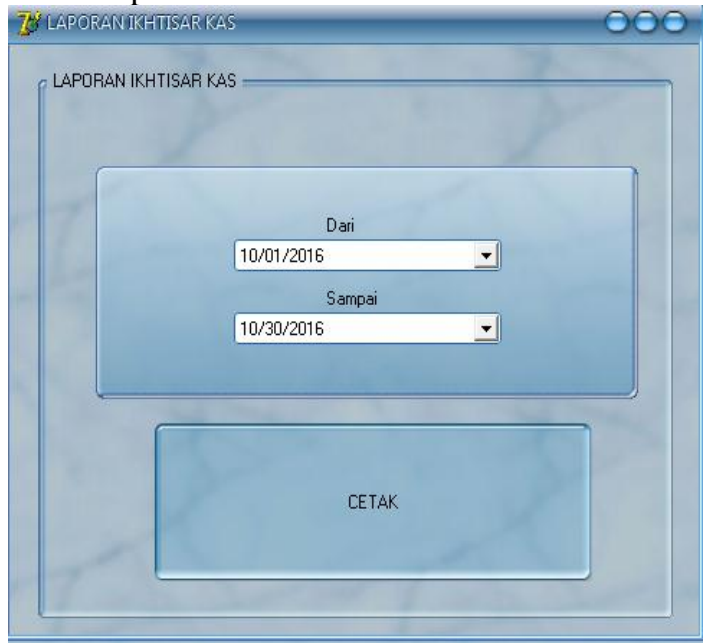

Gambar 12. Laporan Kas Masuk

\section{Laporan Kas Keluar}

Form Laporan Kas Keluar digunakan untuk bukti yang diberikan kepada pimpinan, Form Laporan Kas Keluar dapat dilihat pada Gambar 13.

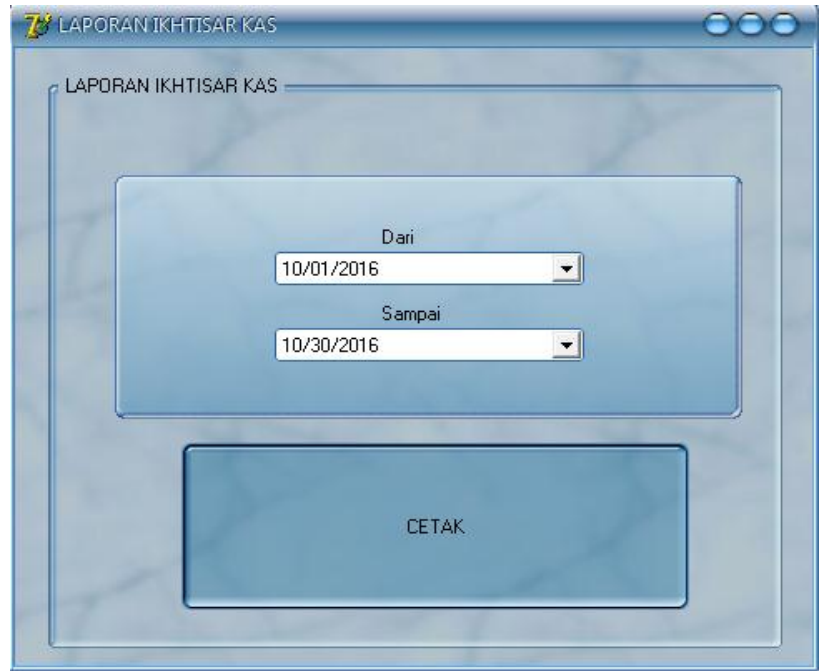

Gambar 13. Laporan Kas Keluar

\section{Kesimpulan Dan Saran}

\subsection{Kesimpulan}

Berdasarkan hasil penelitian terhadap analisis dan implementasi ikhtisar Kas Masjid Istiqomah berbasis Desktop, maka dapat diambil beberapa kesimpulan sebagai berikut :

1. Analisis dan perancangan aplikasi Ikhtisar Kas Masjid Istiqomah berbasis desktop menggunakan UML (Usecase, Activity Diagram, Class Diagram) dapat dilakukan dengan mudah dan dapat diterapkan dengan baik.

2. Implementasi platform aplikasi Borland Delphi 7.0, dan MySQL sangat mudah digunakan untuk pengembangan aplikasi berbasis Desktop.

3. Proses laporan kas masuk, kas keluar dan penyaluran dana pada aplikasi ikhtisar kas masjid Istiqomah dapat berjalan dengan baik walaupun menggunakan.

4. Dalam pengujian yang dilakukan pada aplikasi Ikhtisar Kas masjid Istiqomah tidak ditemukan debag (error), dengan demikian aplikasi ini dapat diimplementasikan langsung pada masjid tersebut.

\subsection{Saran}

Berdasarkan simpulan dari hasil penelitian yang telah dilakukan, maka saran yang dapat diberikan untuk pengembangan lebih lanjut dari analisis dan implementasi Ikhtisar Kas Masjid Istiqomah berbasis Desktop antara lain:

1. Perlu adanya pemeliharaan dan penyempurnaan program aplikasi, hal ini menyangkut kemungkinan pengembangan kembali fasilitas program yang di sesuaikan dengan perkembangan dan kebutuhan masjid.

2. Menempatkan bagian keuangan yang telah memahami prosedur pemakaian program aplikasi analisis dan implementasi Ikhtisar Kas sehingga tidak terjadi 
kesalahan yang dapat menghambat kelancaran proses pelaporan keuangan pada masjid istiqomah.

\section{DAFTAR PUSTAKA}

Ahdan, S., Latih, H. S. and Ramadona, S. (2018) 'Aplikasi Mobile Simulasi Perhitungan Kredit Pembelian Sepeda Motor pada PT Tunas Motor Pratama', Jurnal Tekno Kompak, 12(1), pp. 29-33.

Amarudin, A. and Silviana, S. (2018) 'Sistem Informasi Pemasangan Listrik Baru Berbasis Web Pada PT Chaputra Buana Madani Bandar Jaya Lampung Tengah', Jurnal Tekno Kompak, 12(1), pp. 10-14.

Andri, K. (2007) Analisis \& Perancangan Sistem Informasi. Yogyakarta: Andi.

Chonoles, M. J. and Schardt, J. A. (2003) UML 2 for Dummies. Wiley Publishing, Inc. New York.

Munandar, G. A. and Amarudin, A. (2017) 'Rancang Bangun Aplikasi Kepegawaian Pegawai Negeri Sipil Dan Pegawai Honorer pada Badan Kepegawaian dan Diklat Kabupaten', Jurnal Teknoinfo, 11(2), pp. 5458.

Raymond, G. (2007) Prototype. Jakarta.

Yakup (2012) Pengantar Sistem Informasi. Yogyakarta: Graha Ilmu. 